\title{
SERUM CONCENTRATION OF THYROID HORMONES AND THYROID STIMULATING HORMONE IN ALLOXAN-INDUCED TYPE 1 DIABETIC WISTAR ALBINO RATS
}

\author{
Sher Zamir ${ }^{1}$, Azhar ljaz², Muhammad Umair ${ }^{1}$, Rahat Jan Wazir ${ }^{1}$, Mohammad Salman ${ }^{1}$, Aamir Nazir ${ }^{3}$ \\ Departments of Physiology, ${ }^{1}$ Gomal Medical College, D.I.Khan, ${ }^{2}$ Loralai Medical College, Loralai, ${ }^{3}$ Ayub \\ Medical College, Abbotabad, Pakistan
}

\begin{abstract}
Background: Literature has reported thyroid functional abnormalities in diabetes mellitus. The objectives of this study were to determine and compare the serum concentrations of $T_{3}, T_{4}$ and TSH in alloxan-induced type 1 diabetic and control Wistar albino rats.

Materials \& Methods: It was an experimental animal study on 20 Wistar albino rats, extending over a period of eight weeks. Alloxan, a diabetogenic agent, was used to produce animal models of type 1 diabetes. Animals were divided equally into two groups: control and diabetic. The animals in the diabetic group were injected intraperitoneally with $150 \mathrm{mg} / \mathrm{kg}$ body weight of $10 \%$ alloxan to induce diabetes. After 72 hours, diabetes was confirmed with glucometer (glucose $>350 \mathrm{mg} / \mathrm{dL}$ ). During the course of experiment, one rat in control group and 2 rats in diabetic group died. Blood was collected for estimation of serum concentrations of thyroid hormones, thyroid stimulating hormone at the end of experimental period. Serum $\mathrm{T}_{3}, \mathrm{~T}_{4}$, and TSH were measured using ELISA kits.

Results: At the end of eight weeks, the mean concentration of serum $\mathrm{T}_{3}$ was $0.69 \pm 0.29 \mathrm{ng} / \mathrm{ml}$ and $0.44 \pm 0.02$ $\mathrm{ng} / \mathrm{ml}$ in control and diabetic groups, respectively. The mean concentration of $\mathrm{T}_{4}$ was

$3.78 \pm 1.16 \mu \mathrm{g} / \mathrm{dL}$ and $2.24 \pm 0.86 \mu \mathrm{g} / \mathrm{dL}$ in control and diabetic groups respectively. The mean concentration of TSH was $0.77 \pm 0.20 \mu \mathrm{U} / \mathrm{ml}$ and $1.41 \pm 0.23 \mu \mathrm{U} / \mathrm{ml}$ in control and diabetic groups respectively. The mean serum concentrations of $T_{3}(p=.0025)$ and $T_{4}(p=<.00001)$ were significantly lower in diabetic and that of TSH $(p=<.00001)$ were significantly higher in diabetic than control group.

Conclusion: This study concludes that the serum concentrations of both $\mathrm{T}_{3}$ and $\mathrm{T}_{4}$ are significantly lower and that of TSH is significantly higher in alloxan-induced type 1 diabetic as compared to control group in Wistar albino rats.

KEY WORDS: Alloxan; Diabetes Mellitus Type 1; Diabetes Mellitus Type 2; Thyroid Gland; Thyroid Hormones; Thyroid Diseases; Thyroid Stimulating Hormone.

This article may be cited as: Zamir S, ljaz A, Umair M, Wazir RJ, Salman M, Nazir A. Serum concentration of thyroid hormones and thyroid stimulating hormone in alloxan-induced type 1 diabetic Wistar albino rats. Gomal J Med Sci 2019; 17 (4): 112-6. https://doi.org/10.46903/gjms/17.04.2083
\end{abstract}

\section{INTRODUCTION}

1.1 Background: Diabetes mellitus (DM) is a syndrome of persistent hyperglycemia due to relative or absolute deficiency of insulin leading to its related

\section{Corresponding Author:}

Dr. Sher Zamir

Associate Professor

Department of Physiology

Gomal Medical College, D.I.Khan, Pakistan

E-mail: drsherzamir@gmail.com

Date Submitted: $\quad 31-07-2018$

Date Revised: $\quad$ 02-05-2019

Date Accepted: $\quad$ 01-06-2019 complications. ${ }^{1}$ Diabetes mellitus may be categorized into type 1 and type 2 . In type 1 the cause is an absolute deficiency of insulin secretion. In type 2 diabetes, the cause is a combination of resistance to insulin action and an inadequate compensatory insulin secretory response. ${ }^{2}$

Thyroid diseases and DM are common endocrine abnormalities in clinical practice. Thyroid disorders and DM mutually influence each other. ${ }^{3}$ Both $T_{3}$ and $T_{4}$ contribute to the normal control of glucose metabolism and functions of the pancreas and also diabetes interferes with the functional capability of thyroid gland. Several studies have reported thyroid functional abnormalities in diabetics. 
Perros, et al. reported a prevalence of $13.4 \%$ thyroid disorders in 1,310 adult diabetic patients during annual screening for thyroid disorders; highest in type 1 diabetic females as $31.4 \%$ and lowest in type 2 diabetic males as $6.9 \% .{ }^{4}$ Furthermore, a prevalence of $12.3 \%$ of thyroid dysfunction was found among 1,092 type 2 diabetic patients in Greece. ${ }^{5}$ Akber, et al. reported $16 \%$ patients with type 2 diabetes to have thyroid dysfunction from Saudi Arabia. ${ }^{6}$ Radaideh, et al. reported thyroid dysfunction in $12.5 \%$ of type 2 DM patients $(n=908)$ in year 2000 from Amman, Jordan. ${ }^{7}$

Type 1 DM is associated with thyroid dysfunctions which are the most frequently occurring autoimmune disorders. Kordonouri, et al. reported thyroid autoimmunity in 15 of 335 patients (4.5\%) at type 1 diabetes onset. ${ }^{8}$ Radetti, et al. from Bolzano, Italy reported $3.5 \%$ (55) cases out of 1420 children with type 1 DM having Hashimoto's thyroiditis. ${ }^{9}$ Out of 216 patients with type 1 diabetes, $22(10.0 \%)$ had significantly elevated titres of anti-TPO, $19(8.7 \%)$ of anti-TG and 13 (5.9\%) of both autoantibodies. ${ }^{10}$ Initial screening of children and adolescents with type 1 diabetes, showed $15.4 \%$ of patients having raised anti-TPO and $14.4 \%$ raised anti-TG. ${ }^{11}$ Thyroglobulin autoantibodies were positive in $33 \%$ of the diabetics and thyroid peroxidase autoantibodies were positive in 38\%.12 Ghawil, et al. from Tripoli, Libya has shown that $23.4 \%$ of type $1 \mathrm{DM}$ children had positive anti-microsomal peroxidase antibodies (TPO-Ab) and $7.8 \%$ had positive anti-thyroglobulin (TG-Ab) antibodies; whereas $6.9 \%$ of the patients were positive for both TPO-Ab and TG-Ab. ${ }^{13}$

So, all these studies show that there is interdependent relationship between type $1 \mathrm{DM}$ and thyroid disorders. In Pakistan, the available literature regarding the levels of thyroid hormones and thyroid stimulating hormone in type 1 diabetes is very meager and, at best, inconclusive.

\subsection{Research Objectives (ROs):}

RO 1-3: To determine the serum concentrations of $\mathrm{T}_{3}, \mathrm{~T}_{4}$ and $\mathrm{TSH}$ in alloxan-induced type 1 diabetic and control Wistar albino rats.

RO 4-6: To compare the serum concentrations of $T_{3}$, $\mathrm{T}_{4}$ and TSH in alloxan-induced type 1 diabetic and control Wistar albino rats.

\subsection{Research (Null) Hypotheses (RHs):}

$\mathbf{H}_{\mathbf{0}} \mathbf{1}$ : There is statistically no significant difference in the serum concentrations of $\mathrm{T}_{3}$ in alloxan-induced type 1 diabetic and control Wistar albino rats (RO3).

$\mathbf{H}_{0}$ 2: There is statistically no significant difference in the serum concentrations of $\mathrm{T}_{4}$ in type 1 alloxan-induced diabetic and control Wistar albino rats (RO4).

$\mathbf{H}_{0}$ 3: There is statistically no significant difference in the serum concentrations of TSH in alloxan-induced type 1 diabetic and control Wistar albino rats (RO5).

\section{MATERIALS \& METHODS}

2.1 Design, Duration \& Setting: This experimental animal study was carried out at the Department of Physiology, Postgraduate Medical Institute, Lahore, Pakistan from $16^{\text {th }}$ January 2011 to $15^{\text {th }}$ March 2011. The protocol was approved by Advanced Studies and Research Board of University of Health Sciences, Lahore, Pakistan. As there was intervention but no randomization, so it was a non-randomized quasi experimental design. Experimental group included alloxan-induced type1 diabetic while control group included non-diabetic Wistar albino rats.

2.2 Conduct of Procedure \& Intervention: Twenty healthy Wistar albino rats, including 10 males and 10 females, were obtained from National Institute of Health, Islamabad, Pakistan. The age of the rats was 12 weeks and their average weight was 210 grams. Numbers were allocated as 1 to 10 to males and 11 to 20 to females. Experimental group was allocated S.No. 1 to 5 male \& S.No. 11 to 15 female rats, while control group was allocated S.No. 6 to10 male \& S.No. 15 to 20 female rats.

The rats were acclimatized for two weeks before starting the experiment. Experimental and control groups were kept in separate iron cages under optimum temperature $\left(24 \pm 2^{\circ} \mathrm{C}\right)$ and hygienic conditions with observation of light and dark cycles. These were given water ad libitum. Ordinary/ commercially available rats food was given twice/ day at 8 am and 8 pm@ 12 grams/ rat/ feed.

Alloxan was used to induce type 1 diabetes mellitus in rats of diabetic group. A single dose of alloxan monohydrate (10\%) powder was given in a doze of $150 \mathrm{mg} / \mathrm{kg}$ body weight, dissolved in $3 \mathrm{ml}$ of $0.9 \%$ $\mathrm{NaCl}$ and given as intra-peritoneal injection. Control group rats received the same volume of $0.9 \% \mathrm{NaCl}$ as intra-peritoneal injection. Three days later, DM was confirmed using fasting blood glucose (FBG) by getting a drop of blood from the tails of rats and checking it by glucometer. A rat was labeled to be diabetic if its FBG was more than $130 \mathrm{mg} / \mathrm{dL} .{ }^{14}$ The minimum level of FBG of each of the 10 rats was $>300 \mathrm{mg} / \mathrm{dL}$. During the course of experiment, one female rat in control group and one male and one female rat in diabetic group died. So we were left with nine rats in experimental and eight rats in control group.

2.3 Blood Sample Collection: At the end of eight weeks experimental period, blood was collected from the rats. Samples were collected by cardiac puncture using $5 \mathrm{ml}$ sterile syringes after giving deep ether anesthesia in the morning. Before collecting the blood samples, the animals were kept fasted overnight. From each rat, approximately $5 \mathrm{ml}$ blood was collected and transferred to test tube for estimation of serum concentration of $\mathrm{T}_{3}, \mathrm{~T}_{4}$, and $\mathrm{TSH}$. After centrifuging the blood, serum was separated. Until the time of measurement, serum was stored 
at $-20^{\circ} \mathrm{C}$ for hormones estimation. Enzyme-linked immunosorbent assay (ELISA) Kits (BioCheck, Inc., South San Francisco, CA, USA) were used to measure serum concentrations of thyroid hormones and thyroid stimulating hormone.

2.4 Data Collection \& Data Analysis Plan: Serum concentrations of $\mathrm{T}_{3}, \mathrm{~T}_{4}$ and $\mathrm{TSH}$ were three research variables. The data type for these variables was ratio (numeric). All these were described by mean, minimum, maximum, range and standard deviation, for each group separately for the sample. Estimated parameters for population were given as confidence intervals $(\mathrm{Cl})$ of mean at $95 \%$ confidence level $(\mathrm{CL})$. Each research variable was compared between the two groups through independent-samples t-test. Sample size, mean \& SD for each group, mean difference, $\mathrm{Cl}$ of mean difference, degree of freedom, $t$-value and significance ( $p$-value) were given for each test separately. Data was analyzed by SPSS v.17 (SPSS Inc., Chicago, IL, USA).

\section{RESULTS}

3.1 Descriptive Statistics \& Estimation of Parame- ters: The serum concentration of $\mathrm{T}_{3}$ and $\mathrm{T}_{4}$ and $\mathrm{TSH}$ are given for sample and as $\mathrm{Cl}$ for population. The mean concentration of serum $\mathrm{T}_{3}$ and $\mathrm{T}_{4}$ are lower for diabetic group than control group rats. The mean concentration of serum TSH is higher for diabetic group than control group rats. (Tables 1)

\subsection{Hypotheses Testing:}

$\mathbf{H}_{\mathbf{0}} \mathbf{1}$ : Here the mean serum concentration of $T_{3}$ in diabetic rats was compared to control group animals through independent-samples t-test at alpha .05. As p-value was less than .05, hence $\mathrm{H}_{0} 1$ was proved to be false and rejected, showing the difference to be statistically significant. In simple words, the concentration of serum $\mathrm{T}_{3}$ was found lower in diabetic rats than control group animals. (Table 2)

$\mathbf{H}_{0}$ 2: Here the mean serum concentration of $T_{4}$ in diabetic rats was compared to control group animals through independent-samples t-test at alpha .05. As p-value was less than .05 , hence $\mathrm{H}_{0} 2$ was proved to be false and rejected, showing the difference to be statistically significant. In simple words, the concentration of serum $\mathrm{T}_{4}$ was found lower in diabetic rats than control group animals. (Table 3)

Table 1: Descriptive statistics \& estimation of parameters of thyroid hormones \& thyroid stimulating hormone in diabetic $(n=9)$ and control group $(n=8)$ Wistar albino rats

\begin{tabular}{|l|l|l|l|l|l|l|l|l|}
\hline \multirow{2}{*}{ Variables } & \multirow{2}{*}{ Group } & \multicolumn{6}{|c|}{ Sample Statistics } & \multicolumn{2}{c|}{$95 \%$ Cl of Mean } \\
\cline { 3 - 9 } & & Mean & Min & Max & Range & SD & Lower & Upper \\
\hline \multirow{2}{*}{ T3 $(\mathrm{ng} / \mathrm{ml})$} & Control & 0.6889 & 0.50 & 1.00 & 0.50 & 0.1900 & 0.5428 & 0.8350 \\
\cline { 2 - 9 } & Diabetic & 0.4375 & 0.40 & 0.50 & 0.10 & 0.0517 & 0.3942 & 0.4808 \\
\hline \multirow{2}{*}{ T4 $(\mu \mathrm{g} / \mathrm{dl})$} & Control & 3.7778 & 3.10 & 4.30 & 1.20 & 0.3800 & 3.4856 & 4.0699 \\
\cline { 2 - 9 } & Diabetic & 2.2375 & 1.70 & 2.70 & 1.00 & 0.3502 & 1.9447 & 2.5303 \\
\hline \multirow{2}{*}{$\mathrm{TSH}(\mu \mathrm{U} / \mathrm{ml})$} & Control & 0.7667 & 0.50 & 1.00 & 0.50 & 0.1581 & 0.6451 & 0.8882 \\
\cline { 2 - 9 } & Diabetic & 1.4125 & 1.10 & 1.60 & 0.50 & 0.1807 & 1.2614 & 1.5636 \\
\hline
\end{tabular}

Table 2: Comparison of mean serum concentrations of $\mathrm{T}_{3}$ in alloxan-induced diabetic versus control group Wistar albino rats

\begin{tabular}{|c|c|c|c|c|c|c|c|c|c|}
\hline \multirow{2}{*}{ Groups } & \multirow{2}{*}{$\mathrm{n}$} & \multirow{2}{*}{ Mean } & \multirow{2}{*}{ SD } & \multirow{2}{*}{ Mean difference } & \multicolumn{2}{|c|}{$95 \% \mathrm{Cl}$ of difference } & \multirow{2}{*}{ t-value } & \multirow{2}{*}{ d.f. } & \multirow{2}{*}{$\mathrm{p}$-value (2-tailed) } \\
\hline & & & & & Lower & Upper & & & \\
\hline Control & 9 & 0.6889 & 0.1900 & 0.2513 & .1030 & .3997 & 3.613 & 15 & .0025 \\
\hline Diabetic & 8 & 0.4375 & 0.0517 & \multicolumn{3}{|c|}{ Independent-samples t-test } & \multicolumn{3}{|c|}{$\mathrm{H}_{0} 1$ rejected at $\alpha 0.05$} \\
\hline
\end{tabular}

$\mathrm{n}=$ Sample size, $\mathrm{SD}=$ Standard deviation, d.f. = Degree of freedom

Table 3: Comparison of mean serum concentrations of $T_{4}$ in alloxan-induced diabetic versus control group Wistar albino rats

\begin{tabular}{|c|c|c|c|c|c|c|c|c|c|}
\hline \multirow{2}{*}{ Groups } & \multirow{2}{*}{$\mathrm{n}$} & \multirow{2}{*}{ Mean } & \multirow{2}{*}{ SD } & \multirow{2}{*}{ Mean difference } & \multicolumn{2}{|c|}{$95 \% \mathrm{Cl}$ of difference } & \multirow{2}{*}{ t-value } & \multirow{2}{*}{ d.f. } & \multirow{2}{*}{ p-value (2-tailed) } \\
\hline & & & & & Lower & Upper & & & \\
\hline Control & 9 & 3.7778 & 0.3800 & 1.5403 & 1.1607 & 1.9198 & 8.650 & 15 & $<.00001$ \\
\hline Diabetic & 8 & 2.2375 & 0.3502 & \multicolumn{3}{|c|}{ Independent-samples t-test } & \multicolumn{3}{|c|}{$\mathrm{H}_{0} 2$ rejected at $\alpha 0.05$} \\
\hline
\end{tabular}

$\mathrm{n}=$ Sample size, SD = Standard deviation, d.f. = Degree of freedom 
Table 4: Comparison of mean serum concentrations of TSH in alloxan-induced diabetic versus control group Wistar albino rats

\begin{tabular}{|c|c|c|c|c|c|c|c|c|c|}
\hline \multirow{2}{*}{ Groups } & \multirow{2}{*}{$\mathrm{n}$} & \multirow{2}{*}{ Mean } & \multirow{2}{*}{ SD } & \multirow{2}{*}{ Mean difference } & \multicolumn{2}{|c|}{$95 \% \mathrm{Cl}$ of difference } & \multirow{2}{*}{ t-value } & \multirow{2}{*}{ d.f. } & \multirow{2}{*}{ p-value (2-tailed) } \\
\hline & & & & & Lower & Upper & & & \\
\hline Control & 9 & 0.7667 & 0.1581 & -0.6458 & -0.8209 & -0.4707 & -7.862 & 15 & $<.00001$ \\
\hline Diabetic & 8 & 1.4125 & 0.1807 & \multicolumn{3}{|c|}{ Independent-samples t-test } & \multicolumn{3}{|c|}{$\mathrm{H}_{0} 3$ rejected at $\alpha 0.05$} \\
\hline
\end{tabular}

$\mathbf{H}_{\mathbf{0}}$ 3: Here the mean serum concentration of TSH in diabetic rats was compared to control group animals through independent-samples t-test at alpha .05. As $\mathrm{p}$-value was less than .05 , hence $\mathrm{H}_{0} 3$ was proved to be false and rejected, showing the difference to be statistically significant. In simple words, the concentration of serum TSH was found higher in diabetic rats than control group animals. (Table 4)

\section{DISCUSSION}

Insulin and thyroid hormones show inter-dependence for normal cellular metabolism so that both can mutually influence each other. ${ }^{15}$ Therefore, thyroid dysfunctions can have a major effect on normal control of glucose metabolism, and untreated thyroid disorders can have a great impact on the management of diabetic patients. It has been shown that metabolic alterations caused by DM, or insulin lack itself, can directly affect some functions of thyroid gland. ${ }^{16}$

In this study, we analyzed the serum concentrations of thyroid hormones and thyroid stimulating hormone in type $1 \mathrm{DM}$. Our study showed that the serum concentrations of both $\mathrm{T}_{3}$ and $\mathrm{T}_{4}$ were lower and that of TSH were higher than control group.

\subsection{Thyroid Hormones $\left(T_{3} \& T_{4}\right)$ :}

Similar to our findings are reported by Monajemzadeh, et al. from Ahwaz, Iran for the period from March 2005 to August 2008, including type 1 diabetics $(n 1=75)$ and non-diabetic controls $(n 2=105)$. Serum concentrations of $T_{3}$ and $T_{4}$ were significantly lower in diabetic patients as compared to controls. ${ }^{17}$

Similar findings are by Volzke et al. ${ }^{18}$, from Greifswald, Germany who showed that type 1 diabetic subjects $(n 1=224)$ had lower serum $T_{3}$ levels as compared to normal subjects $(\mathrm{n} 2=3481)$, both groups aged 20-69 years.

Similar to our results are by Rodgers, et al. from London, Ontario, Canada, showed that serum $\mathrm{T}_{4}$ level of streptozotocin-induced type 1 diabetic male Sprague-Dawley rats was lower than controls in the first week and was sustained through the seventh week. ${ }^{19}$

Similar to our findings are from Messina, Italy by Bernasconi, et al..$^{20}$ who revealed that the levels of serum $\mathrm{T}_{4}$ were lower in youngsters non-ketoacidotic type 1 diabetic patients than in controls.
Contrary to our findings are from Lahore, Pakistan by Ditta et al. ${ }^{21}$, including 9-50 years type 1 diabetics $(n 1=50)$ and age \& sex matched healthy controls $(n 2=26)$. The serum concentration of $T_{4}$ was comparable in both the groups.

\subsection{Thyroid Stimulating Hormone (TSH):}

Similar to our findings are reported by Monajemzadeh, et al. from Ahwaz, Iran for the period from March 2005 to August 2008, including type 1 diabetics $(n 1=75)$ and non-diabetic controls $(n 2=105)$. Serum concentrations of TSH were significantly higher in diabetic patients as compared to controls. ${ }^{17}$

Similar to our findings are from Lahore, Pakistan by Ditta et al. ${ }^{21}$, including 9-50 years type 1 diabetics $(n 1=50)$ and age \& sex matched healthy controls $(\mathrm{n} 2=26)$. The serum concentration of TSH was higher in diabetic versus healthy controls.

\section{CONCLUSION}

This study concludes that the serum concentrations of both $\mathrm{T}_{3}$ and $\mathrm{T}_{4}$ are significantly lower and that of TSH is significantly higher in alloxan-induced type 1 diabetic as compared to control group in Wistar albino rats. So, a timely systematic approach to thyroid testing is recommended for early diagnosis of thyroid disorders in diabetic patients.

\section{REFERENCES}

1. Iqbal F, Naz R. Pattern of diabetes mellitus in Pakistan: An overview of problem. Pak J Med Res 2005; 44: 12-5. Not available on net.

2. American Diabetes Association. Diagnosis and Classification of Diabetes Mellitus. Diabetes Care 2009 Jan; 32(Suppl 1): S62-S67. https://doi. org/10.2337/dc09-S062

3. Gray RS, Irvine WJ, Clarke BF. Screening for thyroid dysfunction in diabetics. British medical journal. 1979; 2: 1439. https://doi.org/10.1136/ bmj.2.6202.1439-a

4. Perros P, McCrimmon RJ, Shaw G, Frier BM. Frequency of thyroid dysfunction in diabetic patients: value of annual screening. Diabetic Med 1995; 12(7):622-7. https://doi. org/10.1111/j.1464-5491.1995.tb00553.x

5. Papazafiropoulou A, Sotiropoulos A, Kokolaki A, Kardara M, Stamataki P, Pappas S. Prevalence of thyroid dysfunction among Greek type 2 diabetic patients attending an outpatient clinic. J Clin Med Res 2010; 2:75-8. https://doi.org/10.4021/ 
jocmr2010.03.281w

6. Akbar DH, Ahmed MM, Al-Mughales J. Thyroid dysfunction and thyroid autoimmunity in Saudi type 2 diabetics. Acta Diabetol 2006 May; 43(1): 14-8. https://doi.org/10.1007/s00592-006-0204-8

7. Radaideh ARM, Nusier MK, Amari FL, Bateiha AE, El-Khateeb MS, Naser AS, et al. Thyroid dysfunction in patients with type 2 diabetes mellitus in Jordan. Saudi Med J 2004 Aug;25(8):1046-50.

8. Kordonouri O, Charpentier N, Hartmann R. GADA positivity at onset of type 1 diabetes is a risk factor for the development of autoimmune thyroiditis. Pediatr Diabetes 2011 Feb; 12(1):31-3. https:// doi.org/10.1111/j.1399-5448.2010.00666.x

9. Radetti G, Paganini C, Gentill L, Bernasconi S, Betterle $\mathrm{C}$, Borkenstein $\mathrm{M}$, et al. Frequency of Hashimoto's thyroiditis in children with type $1 \mathrm{di}-$ abetes mellitus. Acta Diabetol 1995; 32(2): 121-4. https://doi.org/10.1007/BF00569570

10. Kordonouri O, Deiss D, Danne T, Dorow A, Bassir C, Grüters-Kieslich A. Predictivity of thyroid autoantibodies for the development of thyroid disorders in children and adolescents with Type 1 diabetes. Diabetic Medicine 2002;19:518-21. https://doi.org/10.1046/j.1464-5491.2002.00699.x

11. Kordonouri O, Hartmann R, Deiss D, Wilms M, Grüters-Kieslich A. Natural course of autoimmune thyroiditis in type 1 diabetes: association with gender, age, diabetes duration, and puberty. Arch Dis Child 2005 Apr; 90(4): 411-4. https:// doi.org/10.1136/adc.2004.056424

12. Lindberg B, Ericsson UB, Ljung R, Ivarsson SA. High prevalence of thyroid autoantibodies at diagnosis of insulin-dependent diabetes mellitus in Swedish children. J Laboratory Clin Med 1997; 130(6): 585-9. https://doi.org/10.1016/S00222143(97)90108-6
13. Ghawil M, Tonutti E, Abusrewil S, Visentini D, Hadeed I, Miotti V, et al. Autoimmune thyroid disease in Libyan children and young adults with type 1 diabetes mellitus. Euro J Pediatr 2011Aug; 170(8): 983-7. https://doi.org/10.1007/s00431010-1386-1

14. Wang Z, Yang Y, Xiang X, Zhu Y, Men J, He M [article in Chinese]. Estimation of the normal range of blood glucose in rats. Wei Sheng Yan Jiu 2010 Mar; 39(2): 133-7.

15. Sathish R, Mohan V. Diabetes and thyroid diseases. Int J Diab Dev Countr 2003; 23: 120-3.

16. Hage M, Zantout MS, Azar ST. Thyroid disorders and diabetes mellitus. J Thyroid Res 2011; 18: 1-7. https://doi.org/10.4061/2011/439463

17. Monajemzadeh SM, Najafian N. Thyroid dysfunction in newly diagnosed type 1 diabetic children. Res J Biol Sci 2009; 4: 506-8.

18. Volzke H, Krohn U, Wallaschofski H, Ludemann J, Ulrich J, Kerner W. The spectrum of thyroid disorders in adult type 1 diabetes. Diabetes Metab Res Rev 2007; 23: 227-33. https://doi. org/10.1002/dmrr.676

19. Rodgers CD, Noble EG, Taylor AW. The effect of STZ-induced diabetes on serum triiodothyronine (T3) and thyroxine (T4) levels in the rat: a seven week time course. Diabetes Res 1994; 26: 93-100.

20. Bernasconi S, Vanelli M, Nori G, Siracusano MF, Marcellini C, Butturini A et al. Serum TSH, T4, T3, FT4, rT3, and TBG in youngsters with non-ketotic insulin-dependent diabetes mellitus. Horm Res 1984; 213-7. https://doi.org/10.1159/000179999

21. Ditta A, Tayyab M, Qavi A, Malik MA, Chaudhary NA. Significance of thyrotropin and thyroxine estimations in type 1 diabetes. J Pak Med Assoc 2001; 51: 349-51.

\section{CONFLICT OF INTEREST \\ Authors declare no conflict of interest. GRANT SUPPORT AND FINANCIAL DISCLOSURE None declared.}

\begin{tabular}{|c|c|}
\hline \multicolumn{2}{|c|}{ AUTHORS' CONTRIBUTION } \\
\hline \multicolumn{2}{|c|}{ The following authors have made substantial contributions to the manuscript as under: } \\
\hline Conception or Design: & SZ, Al \\
\hline Acquisition, Analysis or Interpretation of Data: & SZ, Al, MU, RJW, MS, AN \\
\hline Manuscript Writing \& Approval: & SZ, Al, MU, RJW, MS, AN \\
\hline
\end{tabular}

